\title{
UAV Approach for Detecting Plastic Marine Debris on the Beach: A Case Study in the Po River Delta (Italy)
}

\author{
Yuri Taddia ${ }^{1, *(\mathbb{D}}$, Corinne Corbau ${ }^{2}\left(\mathbb{D}\right.$, Joana Buoninsegni ${ }^{2}$, Umberto Simeoni $^{2}$ and Alberto Pellegrinelli ${ }^{1} \mathbb{D}$ \\ 1 Engineering Department, University of Ferrara, Via Saragat 1, 44122 Ferrara, Italy; \\ alberto.pellegrinelli@unife.it \\ 2 Physics and Earth Science Department, University of Ferrara, Via Saragat 1, 44122 Ferrara, Italy; \\ corinne.corbau@unife.it (C.C.); joana.buoninsegni@unife.it (J.B.); umberto.simeoni@unife.it (U.S.) \\ * Correspondence: yuri.taddia@unife.it; Tel.: +39-0532-974918
}

Citation: Taddia, Y.; Corbau, C.; Buoninsegni, J.; Simeoni, U.;

Pellegrinelli, A. UAV Approach for Detecting Plastic Marine Debris on the Beach: A Case Study in the Po River Delta (Italy). Drones 2021, 5, 140. https://doi.org/10.3390/drones 5040140

Academic Editor: Diego

González-Aguilera

Received: 27 October 2021

Accepted: 22 November 2021

Published: 24 November 2021

Publisher's Note: MDPI stays neutral with regard to jurisdictional claims in published maps and institutional affiliations.

Copyright: (c) 2021 by the authors. Licensee MDPI, Basel, Switzerland. This article is an open access article distributed under the terms and conditions of the Creative Commons Attribution (CC BY) license (https:/ / creativecommons.org/licenses/by/ $4.0 /)$.

\begin{abstract}
Anthropogenic marine debris (AMD) represent a global threat for aquatic environments. It is important to locate and monitor the distribution and presence of macroplastics along beaches to prevent degradation into microplastics (MP), which are potentially more harmful and more difficult to remove. UAV imaging represents a quick method for acquiring pictures with a ground spatial resolution of a few centimeters. In this work, we investigate strategies for AMD mapping on beaches with different ground resolutions and with elevation and multispectral data in support of RGB orthomosaics. Operators with varying levels of expertise and knowledge of the coastal environment map the AMD on four to five transects manually, using a range of photogrammetric tools. The initial survey was repeated after one year; in both surveys, beach litter was collected and further analyzed in the laboratory. Operators assign three levels of confidence when recognizing and describing AMD. Preliminary validation of results shows that items identified with high confidence were almost always classified properly. Approaching the detected items in terms of surface instead of a simple count increased the percentage of mapped litter significantly when compared to those collected. Multispectral data in near-infrared (NIR) wavelengths and digital surface models (DSMs) did not significantly improve the efficiency of manual mapping, even if vegetation features were removed using NDVI maps. In conclusion, this research shows that a good solution for performing beach AMD mapping can be represented by using RGB imagery with a spatial resolution of about $200 \mathrm{pix} / \mathrm{m}$ for detecting macroplastics and, in particular, focusing on the largest items. From the point of view of assessing and monitoring potential sources of MP, this approach is not only feasible but also quick, practical, and sustainable.
\end{abstract}

Keywords: unmanned aerial vehicle (UAV); anthropogenic marine debris (AMD); marine litter; macroplastics; microplastics; multispectral camera

\section{Introduction}

The presence of anthropogenic marine debris (AMD) along coastlines globally is one of most critical pollution issues to date [1-8]. In particular, plastics represent from 60 to $95 \%$ of the global marine litter in the oceans [9-12]; therefore, understanding the dynamics in which they originate, move, and accumulate is crucial [13]. The monitoring of plastic debris abundance in the marine environment [14-16] is important for assessing the potential impact of measures adopted to reduce the presence of plastic AMD. This work can be complicated by large spatial and temporal heterogeneity in the amount of plastic debris, as pointed out by Ryan et al. [17]. Surveys at sea can sample floating [18] and suspended debris using a manta trawl net or sample litter on the seabed [19] with submersibles or remote-operated vehicles or trawling equipment. However, most of the studies show that AMD accumulates along beaches, and hence beach surveys [20,21] are not only necessary but also represent the most common monitoring method for macro-debris. That said, beach cleanups can alter litter loads and abundance on beaches, and beach dynamics can 
introduce additional variables in monitoring changes in the amount and composition of plastic debris [22]. Spatial distribution patterns of litter in sandy littorals have thus been investigated $[23,24]$, finding that differences are present, with embryo dune and mobile dune habitats showing the highest frequency of litter [25]. Plastic AMD follows these distribution patterns; modeling approaches can help to predict both the distribution [26] and marine litter storm wash-outs [27].

On the basis of size, it is possible to divide plastic fragments into micro-, meso-, and macroplastics. In the literature, several boundary values between these classes have been proposed, both from scholars and institutional reports (see Hartmann et al. [28], Figure 1). Ryan et al. [17], for instance, adopted the following classification: microplastic (MP, $<5 \mathrm{~mm}$ ), mesoplastic $(2-20 \mathrm{~mm})$, and macroplastic $(>20 \mathrm{~mm})$. On the other hand, the Guidance on Monitoring of Marine Litter in European Seas [29] suggested a different threshold (i.e., $2.5 \mathrm{~cm}$ ) for macroplastics. Micro-, meso-, and macroplastics are strictly connected to each other, because fragmentation and degradation processes boost the concentration of MPs in the marine environment that usually enter the ocean as macroplastics [30,31], even if a release of MPs can also come from other sources, such as solid waste landfill leachate [32] and tributary river ecosystems [33]. The European Union has financed various projects on the matter of MPs and the presence of solid litter inside the Adriatic Sea. In particular, among the multitude of projects, the DeFishGear project aimed to address the problem of marine litter pollution and the consequent economic impact on coastal communities, to monitor and reduce the quantity of MPs in the marine environment, and to develop an approach for the measurement and monitoring of marine litter and MPs on coasts, in the sea, and on seabeds [34]. The average beach litter density found for the Adriatic and Ionian macroregion within this study is $0.67 \mathrm{items} / \mathrm{m}^{2}$ [35]. Using an approach based on the Clean-Coast Index (CCI) [36] for computing the local beach cleanliness as a parameter to evaluate the local pollution, the cleanliness of most of the surveyed beaches was classified as clean or moderate. Hence, characterizing the presence of macroplastics along beaches is crucial in order to detect potential sources of future MPs as well as to develop and organize impact mitigation plans and specific litter removal interventions. For this task, various techniques can be used [37]; in particular, we can consider (i) direct methods that require mapping carried out by operators on the beach, whereas (ii) indirect ones can be performed in a remote way in less time.

Unmanned aerial vehicles (UAVs) provide a flexible platform for carrying compact digital cameras to acquire pictures of the coastal environment [38-40]. A quick remote method can hence be represented by the use of UAVs equipped with instruments able to detect the AMD. Images collected during UAV missions can thus be used for identification, even in real time. The level of detail in detecting the AMD is related to the ground sample distance (GSD), which depends on the characteristics of the camera used for acquiring pictures and on the flight altitude of the drone. UAV-based images have been used to describe dune morphodynamics [38,41], including cases of small formations [42,43] in the coastal environment, and therefore represent an innovative, efficient, and cost-effective tool for litter mapping [44-46]. Moreover, the use of drones with an onboard real-time kinematic (RTK) global navigation satellite system (GNSS) receiver reduces, or even eliminates, the need for deploying ground control points (GCPs) during the acquisition of images in order to achieve a final centimeter-level accuracy [47-49] in positioning AMD items.

The NET4mPLASTIC project aims to collect data on the distribution and composition of MPs along the Croatian and Italian coastal and marine areas. In fact, MPs have a great impact on species, environment, water quality, ecosystems, and the economy since they are present everywhere in the marine environment [31], fisheries, and aquaculture [30]. Hence, one of the project purposes is to investigate strategies for the mapping of potential MP sources on the beaches.

Since the deployment of UAVs is quite simple and allows one to cover a broad portion of beach, in this research, we focused on the use of different photogrammetric products retrieved by the image processing of UAV-acquired datasets. Moreover, we assessed the 
results achieved (i) by varying the spatial resolution of images, (ii) by using information provided by an elevation model, and (iii) by using multispectral (MS) data. Finally, we used two operators with a different level of expertise in the knowledge of the coastal environment every time. The novelty of this work is exploring all of these aspects to describe the optimal method for performing UAV-based mapping of litter and macroplastics on the beaches.

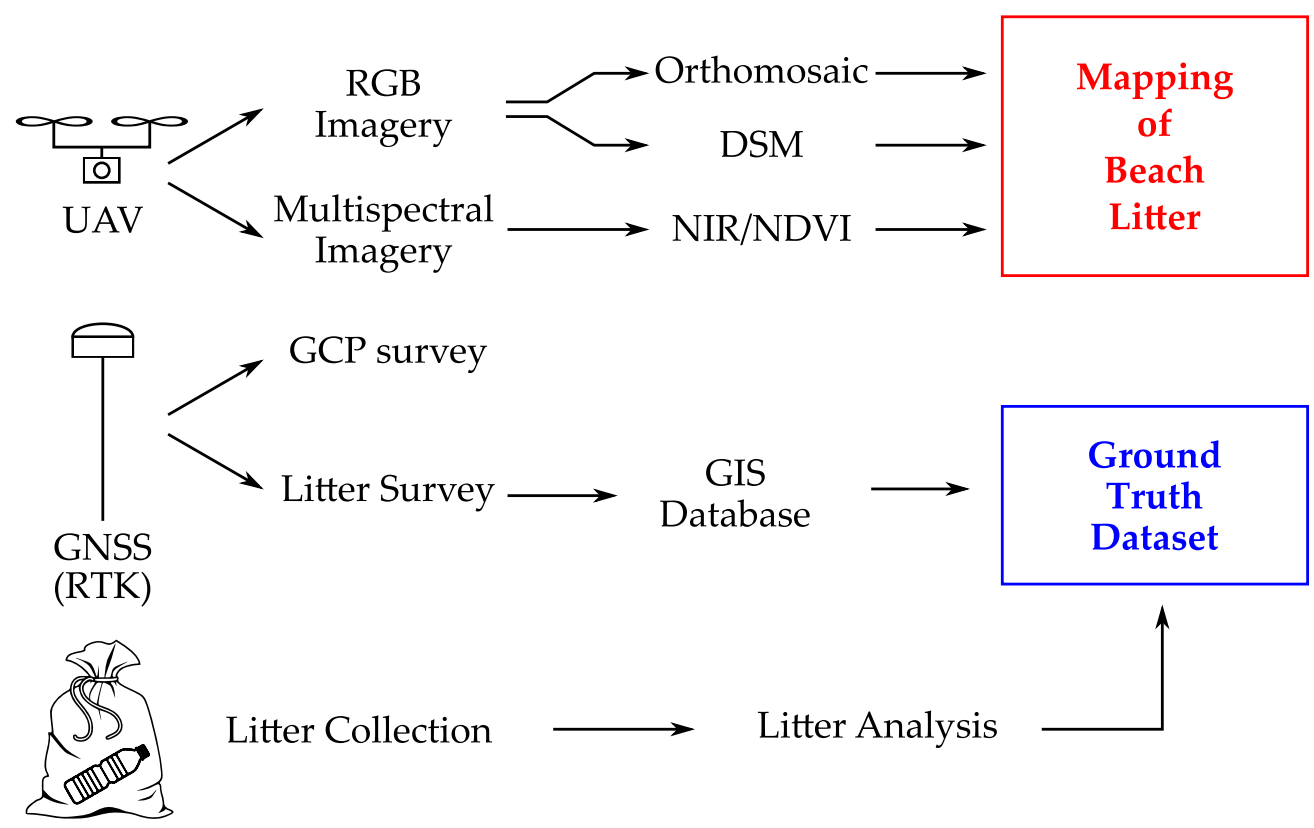

Figure 1. Description of the methodology adopted in this work.

\section{Materials and Methods}

In this section, we present the methodology from the in situ data collection to the mapping and classification of the marine litter based on UAV-derived data. Figure 1 summarizes the overall set of information acquired and processed to obtain (i) the mapping of AMD and (ii) a ground truth dataset.

\subsection{Test Site Description}

In this work, we selected a test site located in the Natura 2000 site of Sacca di GoroFoce del Po di Volano in Northern Italy (Figure 2a). This site is one of the NET4mPLASTIC project sites used for characterizing the origin, abundance, distribution, and potential accumulation area of MPs and co-pollutants in marine systems. In fact, Po river $(652 \mathrm{~km}$ long) is the main Italian river, and its basin covers an area of $71,000 \mathrm{~km}^{2}$, which flows through 3200 municipalities in 7 regions. Since the Po river collects the water of the entire basin of the Pianura Padana, it carries a notable amount of material into the Adriatic Sea. In this way, a test site within this river delta (Figure 2b) represents an area of high macroplastic and litter accumulation. The examined coast stretch is situated in the northern part of the Lidi di Comacchio, which is a well-known Italian seaside resort in the Northern Adriatic Sea. The beach that is the focus of this research is at Lido di Volano, which is located in a microtidal context, has a NNE-SSW orientation, and is dominated by low wave energy. The beach consists of fine sand and has a morphology with well-developed single swash bar systems. The beach width ranges between 20 and $60 \mathrm{~m}$.

For the experiment, ten transects (i.e., sampling units) have been staked out (Figure 2c), and 4 to 5 of them have been surveyed for the research presented here. Each transect had a width of $10 \mathrm{~m}$ and an approximate length of $45-50 \mathrm{~m}$, from the shoreline to the foredune. 


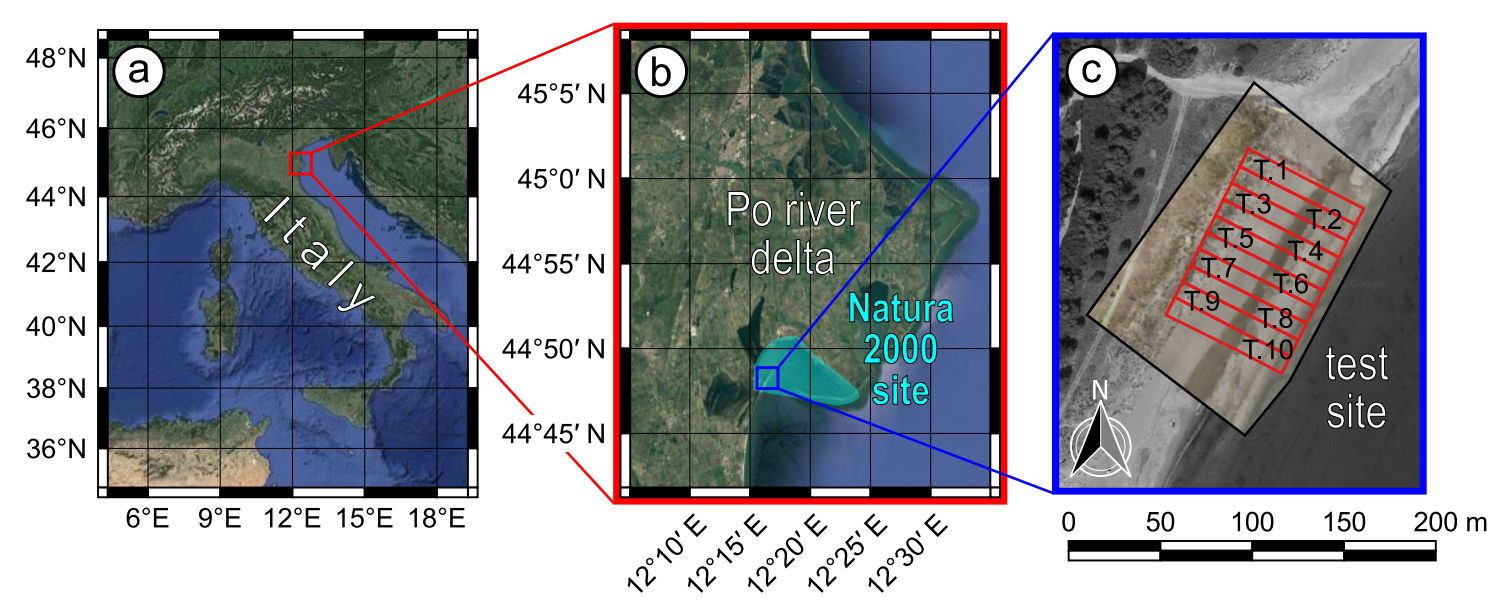

Figure 2. Location of the test site: (a) Po river delta in Northern Italy; (b) zone of the Natura 2000 site of Sacca di Goro-Foce del Po di Volano; (c) the test site divided into transects. (background images from Google Earth).

\subsection{In Situ Operations}

\subsubsection{UAV Image Acquisition}

The acquisition of UAV image datasets has been performed using a DJI Phantom 4 RTK (DJI-P4RTK, Figure 3a) and a DJI Phantom 3 Professional (DJI-P3P, Figure 3b). Both UAVs were provided with their own RGB camera (20 Megapixel for DJI-P4RTK and 12 Megapixel for DJI-P3P). The DJI-P3P was also equipped with a Micasense RedEdge M multispectral camera (1.2 Megapixel) able to acquire data in the blue, green, red, red edge, and near infrared (NIR) wavelengths. The main differences between the aircrafts were (i) that the app used for the mission planning of DJI-P3P (Pix4D Capture) allowed us to fly at a minimum altitude of $10 \mathrm{~m}$ above ground level, whereas the DJI-P4RTK app integrated into the remote controller (GS RTK) had the limitation of a minimum altitude of $25 \mathrm{~m}$, and (ii) that the DJI-P4RTK was used to acquire image datasets with a centimeter-level georeferencing accuracy due to an on-board multi-frequency, multi-constellation GNSS receiver in RTK mode. A base receiver (DJI Mobile Station 2, Figure 3c) was set up on a benchmark whose coordinates were surveyed using a Topcon GR-3 geodetic receiver in Network-RTK (NRTK). Alternatively, an approach based on NRTK can also be used for drone navigation. Ground control points (GCPs) were deployed using targets prior to image acquisition and surveyed in NRTK mode (Figure 3d) in order to achieve a centimeterlevel accuracy for DJI-P3P image datasets as well. Each GCP position was collected through a $30 \mathrm{~s}$ stop-and-go method. In this way, data collection was framed in the official Italian reference system ETRS89-ETRF2000(2008.0). Topcon GR-3 in NRTK mode was also used for the ground survey of beach litter (Figure 3e) as reported in Section 2.2.2.

The data collection was repeated twice, on 25 October 2019 and 5 November 2020. Automatic flight missions were planned in order to map the test site extent at different altitudes. In fact, the ground sample distance (GSD) was varied to assess mapping results. Altitudes and corresponding GSDs are reported in Tables 1 and 2. Flight missions at very low altitudes were focused on a smaller amount of transects. 

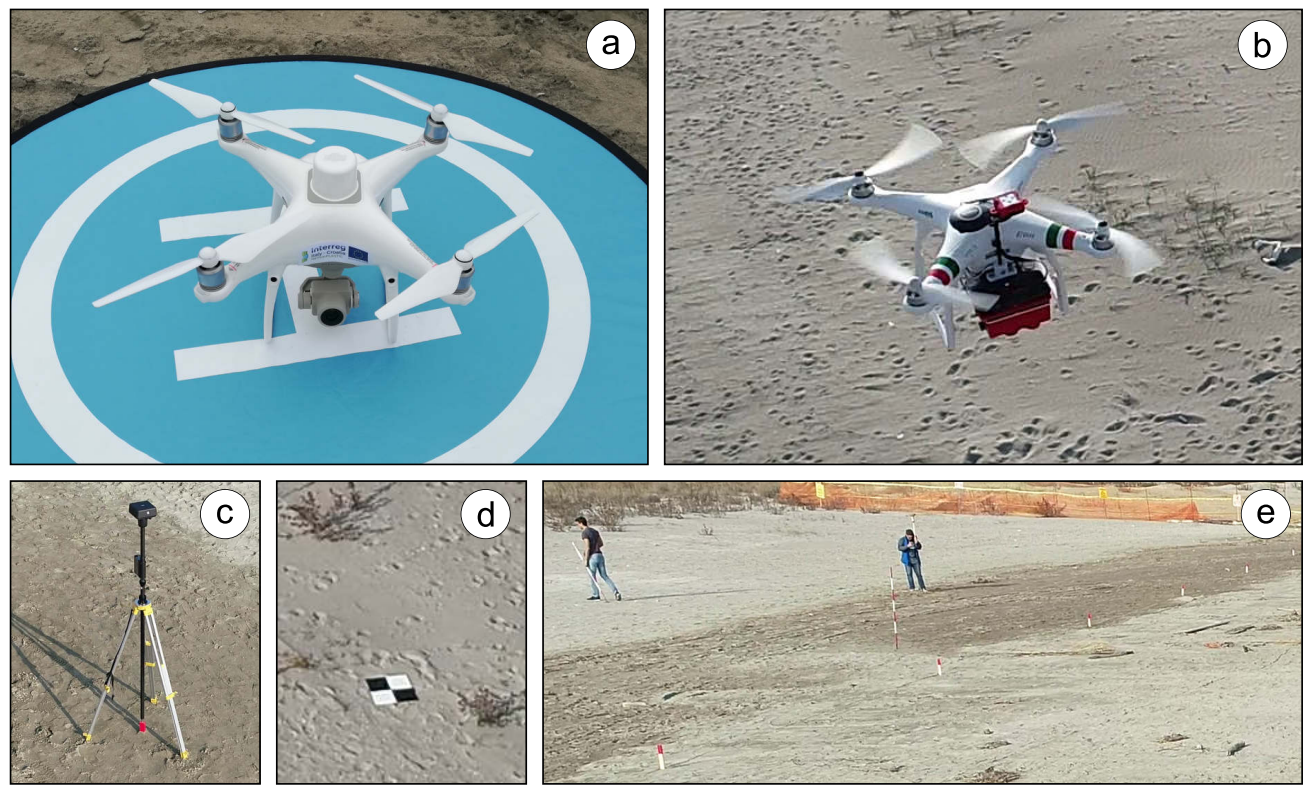

Figure 3. (a) DJI Phantom 4 RTK (DJI-P4RTK) aircraft; (b) DJI Phantom 3 Professional (DJI-P3P) with Micasense RedEdge M multispectral camera; (c) setup of the base station receiver for RTK operations of the DJI-P4RTK; (d) example of ground control point (GCP); (e) GNSS survey of GCPs and litter items.

Table 1. Flight altitudes and ground sample distance (GSD)—survey in October 2019.

\begin{tabular}{ccccc}
\hline Aircraft & Altitude & Camera & GSD & Transects \\
\hline DJI-P3P & $10 \mathrm{~m}$ & $\begin{array}{c}\text { RGB camera } \\
\text { Micasense } \\
\text { RedEdge M }\end{array}$ & $\approx 4 \mathrm{~mm}$ & T.1 to T.5 \\
\hline DJI-P4RTK & $10 \mathrm{~m}$ & RGB camera & $\approx 7 \mathrm{~mm}$ & T.1 to T.5 \\
\hline
\end{tabular}

Table 2. Flight altitudes and ground sample distance (GSD)—survey in November 2020.

\begin{tabular}{ccccc}
\hline Aircraft & Altitude & Camera & GSD & Transects \\
\hline \multirow{2}{*}{ DJI-P3P } & $10 \mathrm{~m}$ & RGB camera & $\approx 4 \mathrm{~mm}$ & T.1 to T.4 \\
& $10 \mathrm{~m}$ & $\begin{array}{c}\text { Micasense } \\
\text { RedEdge M }\end{array}$ & $\approx 7 \mathrm{~mm}$ & T.1 to T.4 \\
\hline DJI-P4RTK & $25 \mathrm{~m}$ & RGB camera & $\approx 7 \mathrm{~mm}$ & all \\
\hline
\end{tabular}

\subsubsection{Direct Survey of Marine Litter: The Ground Truth Dataset}

After flying the drone over the test site and before collecting the material, a litter survey was performed at a level of transect, as previously mentioned in Section 2.2.1. Items larger than $2.5 \mathrm{~cm}$ were surveyed, collecting both the position and a detailed picture. Data acquired in this way were used to generate a database of AMD spatial distribution. The ground truth dataset was created, combining the GNSS RTK position collected with a description of the item derived from the picture. The color was also assessed. Figure 4 illustrates the position of items surveyed in each transect from T.1 to T.4 in 2020 (a similar survey was performed in 2019). 


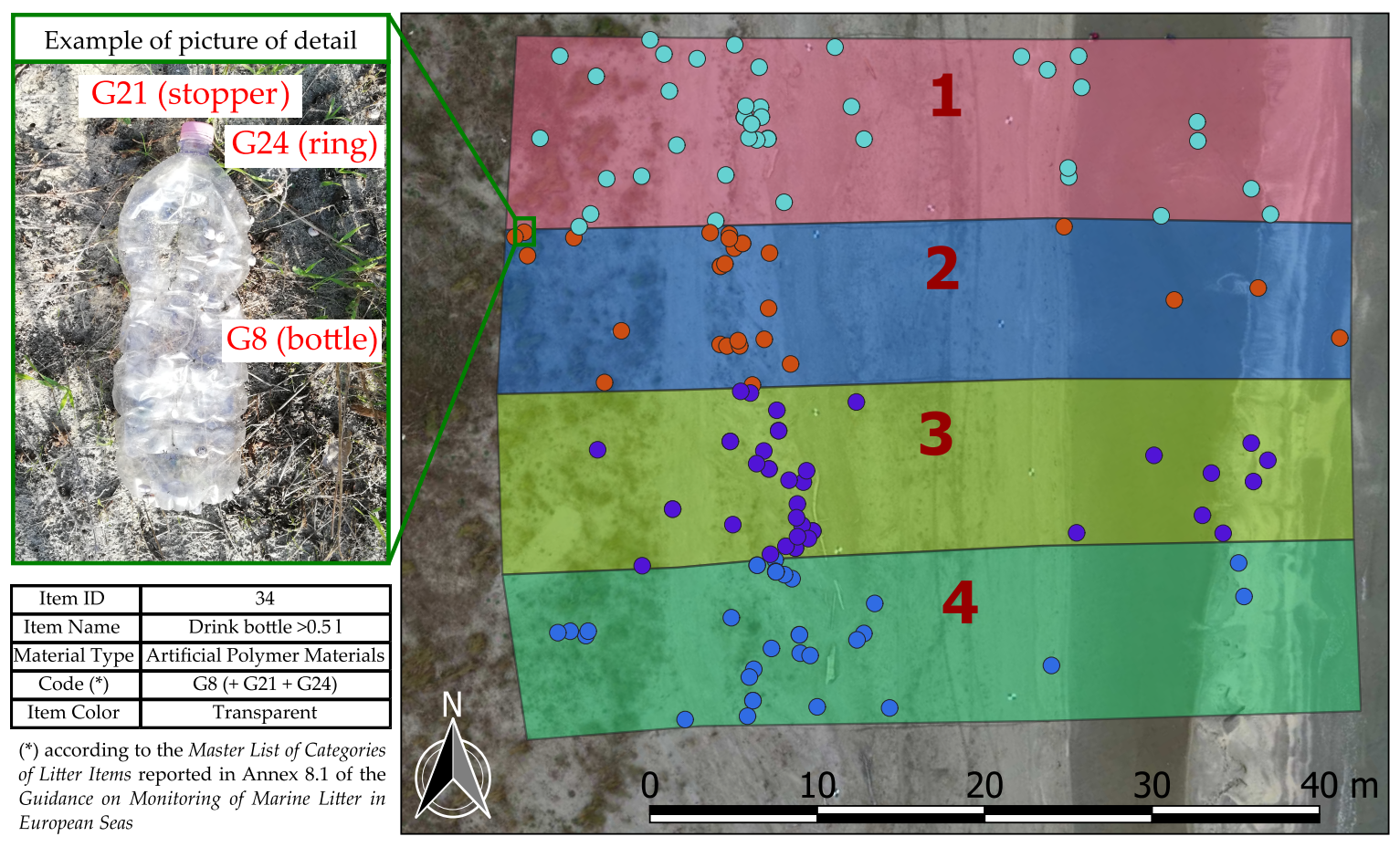

Figure 4. Ground truth dataset of surveyed litter items per transect (2020).

\subsection{Data Processing and Analyses}

\subsubsection{Generation of Orthomosaics and DSMs}

UAV image datasets were used to reconstruct a photogrammetric model of the beach. For this task, we used Agisoft Metashape to generate the orthomosaic of test site transects. Accurate georeferencing was obtained using RTK camera locations for DJI-P4RTK drone or with a set of well-distributed ground control points (GCPs) for the non-RTK drone DJI-P3P during image alignment. The workflow of data processing from acquired image datasets to orthomosaics and the digital surface model (DSMs) is summarized in Figure 5. In particular, we generated RGB and near-infrared (NIR) orthomosaics and the NDVI map. Images with the smallest GSD_thus, for the configuration when flying at a $10 \mathrm{~m}$ altitude with the DJI-P3P aircraft-were also used to reconstruct a DSM of the beach. In fact, the elevation variation across the beach profile can provide additional information useful for classifying the litter properly. Visualizing the DSM with hillshade rendering or extracting cross-section profiles on the fly in a geographic information system (GIS) environment may allow operators to evaluate the shape of items with more confidence. However, since the generation of a DSM with a poorer spatial resolution on the ground (higher GSDs) allowed one to identify and classify items of large dimension, we decided not to generate DSMs for flights carried out at altitudes higher than $10 \mathrm{~m}$. All the georeferenced orthomosaics and DSMs were exported to further proceed with image-based litter detection. Products obtained after image processing are reported in Table 3.

Table 3. Image data processing outputs.

\begin{tabular}{cccccc}
\hline Aircraft & Altitude & Camera & $\begin{array}{c}\text { RGB } \\
\text { Orthomosaic }\end{array}$ & $\begin{array}{c}\text { Multispectral } \\
\text { Data } \\
\text { (NIR, NDVI) }\end{array}$ & DSM \\
\hline \multirow{2}{*}{ DJI-P3P } & $10 \mathrm{~m}$ & RGB camera & yes & no & yes \\
& $10 \mathrm{~m}$ & $\begin{array}{c}\text { Micasense } \\
\text { RedEdge M }\end{array}$ & yes & yes & no \\
\hline DJI-P4RTK & $25 \mathrm{~m}$ & RGB camera & yes & no & no \\
\hline
\end{tabular}




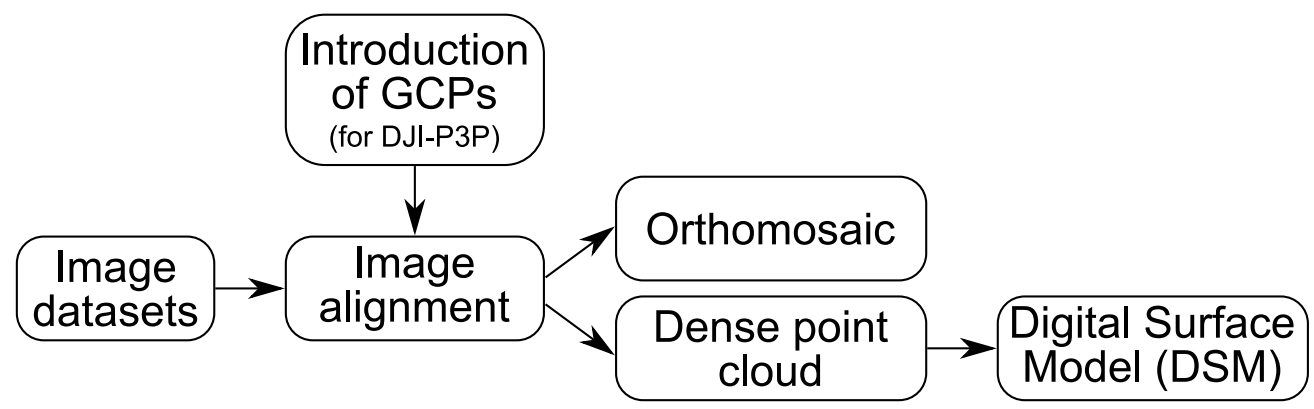

Figure 5. Data processing for UAV image datasets.

\subsubsection{Mapping and Classification of the Litter}

Orthomosaics generated using different ground resolution datasets were used to recognize the presence of litter items on the beach, together with NIR-NDVI data and DSM. Since it is important to establish levels of operator uncertainty during this process, we assumed 3 levels of confidence as follows:

- CL 1: the operator is sure that both the detection and the classification of the item are correct; a description of the item is provided during the mapping process;

- CL 2: the operator is sure that the item is litter, but unsure about the type (difficult to classify); a description of the item may be provided during mapping process;

- CL 3: the operator identifies something that probably is litter, but that may be also a natural element that appears similar to litter on the orthomosaic; a description of the item cannot be provided during mapping process.

Additionally, the level of experience and expertise of the operator in knowing the coastal environment and recognizing the marine litter can be different. For this reason, we selected two types of operators: operator 1 has almost no experience in marine litter mapping and about geomorphological aspects of beaches, while operator 2 is skilled and an expert in these fields. Operator 1 was different for the 2019 and 2020 surveys; operator 2 was the same for both surveys.

\subsubsection{Collection of Beach Litter and Laboratory Analysis}

After image acquisition, all the marine litter on the beach was collected for each transect and divided into transect zones (e.g., dune, beach, see Figure 6). All the material was analyzed in the laboratory to identify and classify each item according to the Master List of Categories of Litter Items reported in Annex 8.1 of the Guidance on Monitoring of Marine Litter in European Seas [29] (see Table 4).
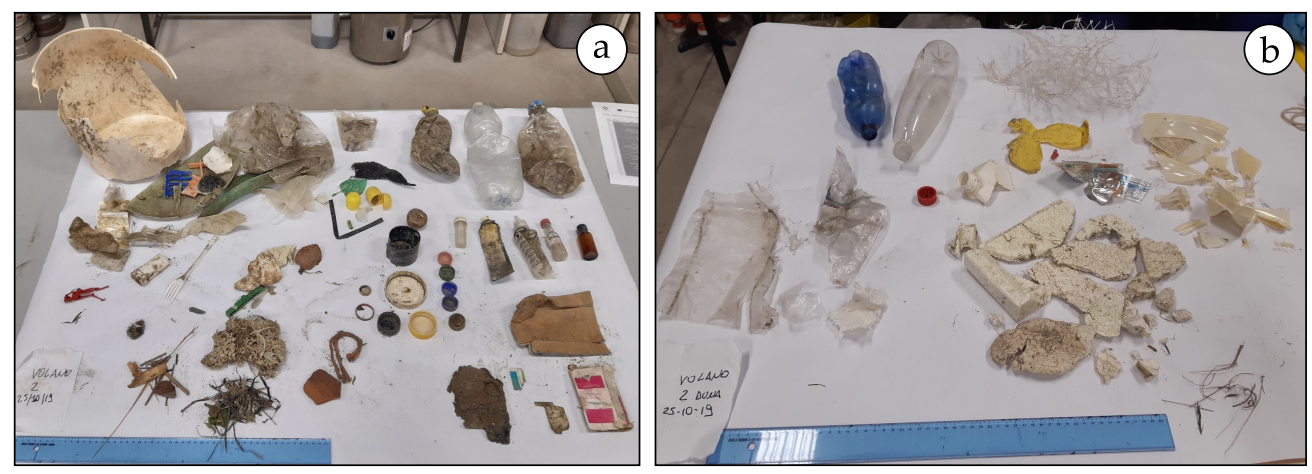

Figure 6. Litter collected in transect T.2 in October 2019: (a) on the beach; (b) in the dune. 
Table 4. Laboratory analysis results for the litter collected in transect T.2 in October 2019.

\begin{tabular}{|c|c|c|}
\hline Class & Material & Number \\
\hline \multicolumn{3}{|c|}{ Zone: BEACH } \\
\hline G82 & Artificial polymer materials & 3 \\
\hline G124 & Artificial polymer materials & 1 \\
\hline G125 & Rubber & 1 \\
\hline G21 & Artificial polymer materials & 5 \\
\hline G24 & Artificial polymer materials & 1 \\
\hline $\mathrm{G} 23+\mathrm{G} 22$ & Artificial polymer materials & 4 \\
\hline $\mathrm{G} 100+\mathrm{G} 23$ & Artificial polymer materials & 1 \\
\hline $\mathrm{G} 200+\mathrm{G} 23+\mathrm{G} 178$ & $\begin{array}{l}\text { Glass/ceramics + Artificial } \\
\text { polymer materials + Metal }\end{array}$ & 2 \\
\hline G11 & Artificial polymer materials & 1 \\
\hline $\mathrm{G} 100+\mathrm{G} 23$ & Artificial polymer materials & 1 \\
\hline G13 & Artificial polymer materials & 2 \\
\hline G82 & Artificial polymer materials & 1 \\
\hline $\mathrm{G} 34+\mathrm{G} 79+\mathrm{G} 89$ & Artificial polymer materials & 16 \\
\hline $\mathrm{G} 4$ + G5 + G66 & Artificial polymer materials & 9 \\
\hline $\mathrm{G} 90+\mathrm{G} 79$ & Artificial polymer materials & 10 \\
\hline G134 & Rubber & 1 \\
\hline G204 & Glass/ceramics & 1 \\
\hline G49 & Artificial polymer materials & 1 \\
\hline G148 + G156 & Paper/Cardboard & 6 \\
\hline G62 & Artificial polymer materials & 1 \\
\hline G126 & Rubber & 1 \\
\hline \multicolumn{2}{|c|}{ Total (with no natural vegetation-related elements) } & 69 \\
\hline \multicolumn{3}{|c|}{ Zone: DUNE } \\
\hline G82 & Artificial polymer materials & 16 \\
\hline G10 & Artificial polymer materials & 20 \\
\hline $\mathrm{G} 21+\mathrm{G} 8+\mathrm{G} 7$ & Artificial polymer materials & 2 \\
\hline G78 & Artificial polymer materials & 3 \\
\hline G45 & Artificial polymer materials & 2 \\
\hline G22 & Artificial polymer materials & 1 \\
\hline G14 & Artificial polymer materials & 5 \\
\hline G25 & Artificial polymer materials & 1 \\
\hline \multicolumn{2}{|c|}{ Total (with no natural vegetation-related elements) } & 50 \\
\hline
\end{tabular}

\section{Results}

\subsection{Validation of Image-Based Litter Description}

In order to evaluate the accuracy with which operators described litter items, we carried out a classification accuracy assessment. The description of the items identified by the operators was compared with the detailed picture of the object when available (see Table 5).

Table 5. Litter items for which a picture of detail was captured in October 2019. Litter items for which the operator descriptions were correct (October 2019 dataset).

\begin{tabular}{lcccc}
\hline & \multicolumn{2}{c}{$\begin{array}{c}\text { Items with a } \\
\text { Picture of Detail }\end{array}$} & \multicolumn{2}{c}{$\begin{array}{c}\text { Items } \\
\text { Described Properly }\end{array}$} \\
\cline { 2 - 5 } & CL 1 & CL 2 & CL 1 & CL 2 \\
\hline Op. 1-P4RTK-25 m & 18 & 12 & $18(100 \%)$ & $5(42 \%)$ \\
Op. 2-P4RTK-25 m & 15 & 15 & $15(100 \%)$ & $5(33 \%)$ \\
Op. 1-P3P-10 m & 24 & 17 & $24(100 \%)$ & $6(35 \%)$ \\
Op. 2-P3P-10 m & 22 & 11 & $22(100 \%)$ & $6(55 \%)$ \\
Op. 1-P3P-10 m + MS & 24 & 18 & $24(100 \%)$ & $6(33 \%)$ \\
Op. 2-P3P-10 m + MS & 28 & 18 & $28(100 \%)$ & $6(33 \%)$ \\
\hline
\end{tabular}

These results shows that all of the CL 1 items were properly recognized and described by the operators. Most of the CL 2 items were not described by the operators, due to the higher level of uncertainty implicitly associated with the difference between assigning a CL 1 or a CL 2 class. However, Figure 7 shows that only a few items were not properly described by the operators, while most of them, when described, were properly recognized. 


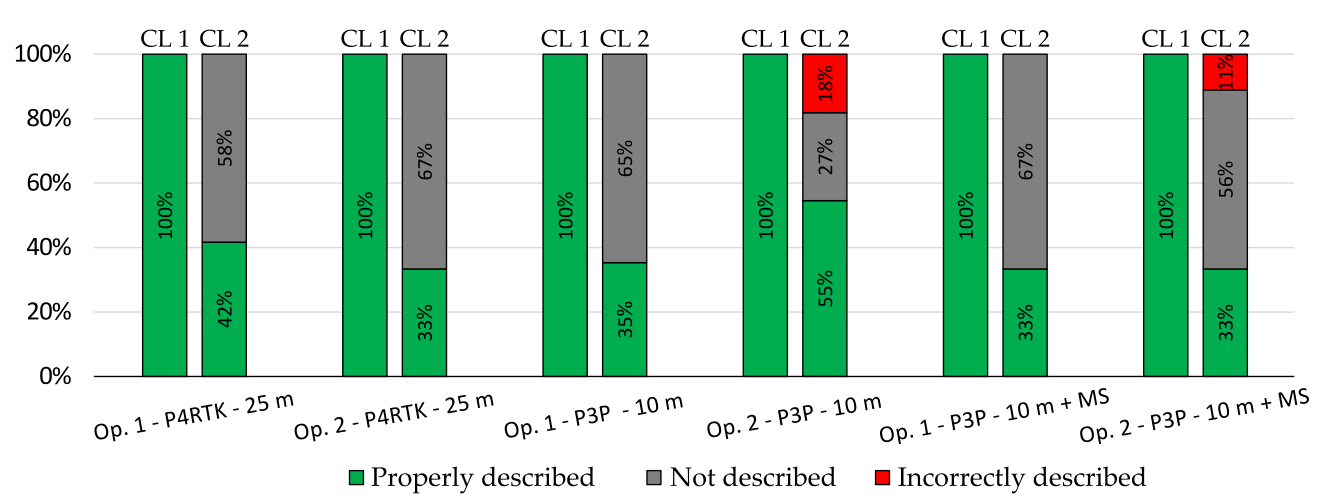

Figure 7. Results of the accuracy assessment of operator descriptions.

\subsection{First Campaign (2019)}

The identification and classification of litter through a manual mapping based on orthomosaics at different ground spatial resolution and with the additional information provided by the near-infrared wavelengths produced the results reported in Figure 8. Both operators preferred to assign CL 2 in most cases. In fact, the classification of litter type was found to be generally hard. Larger items or items with a well-defined shape (e.g., bottles) are easy to identify and hence assigned CL 1. However, a variety of objects that are quite different from the background sand texture are distinguishable, but not recognizable. In addition, there is no guarantee that those objects are litter. Operator 1, less expert than operator 2, preferred to assign CL 3 instead of CL 2 for many items, unsure of whether the object was actually litter.
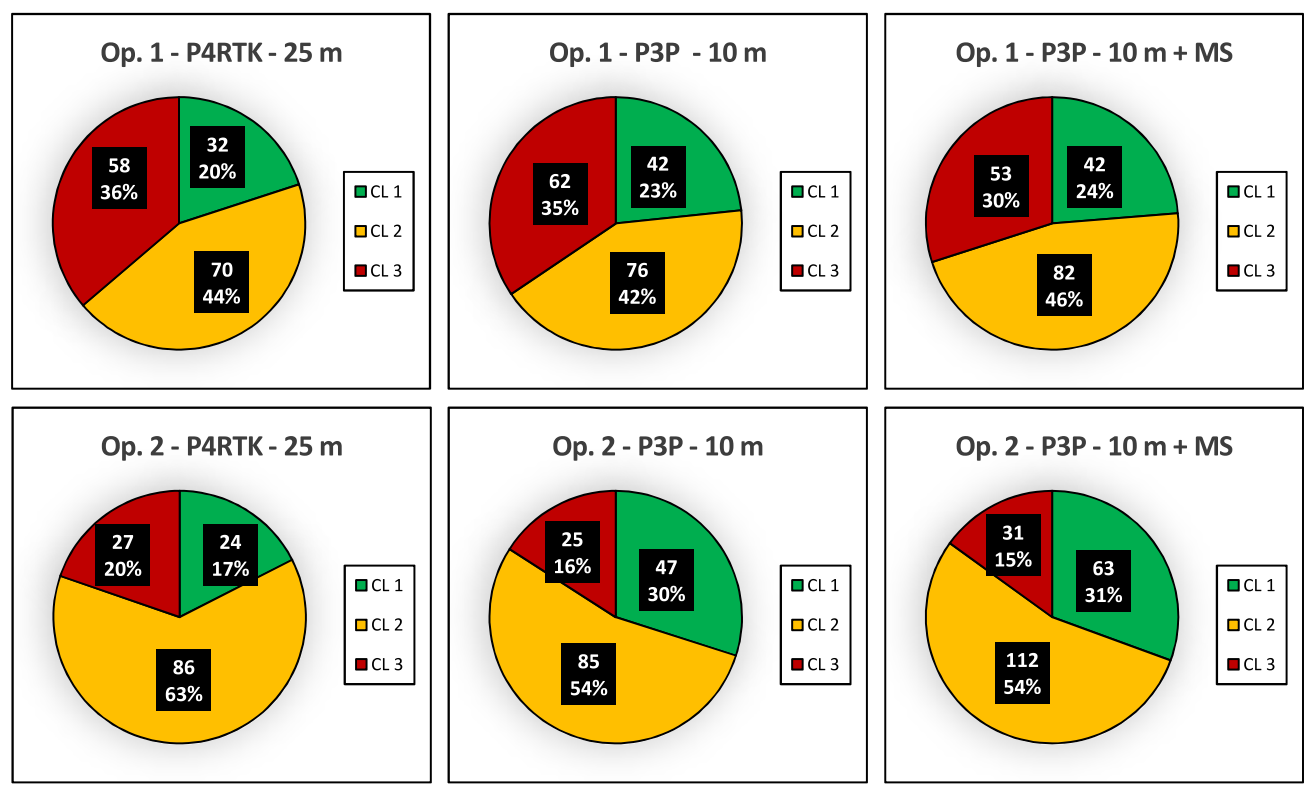

Figure 8. Number of items recognized through manual image mapping by different operators with different image datasets (2019).

While identifying every piece of litter was not possible, litter collection provided the total number of objects that were present in each transect at the time of the survey. Figure 9 shows the number of total items recognized by the operators using the different levels of information available and those collected in the field. For transects T.2, T.3., and T.4, the collection was extended up to the dune zone, where the largest items were collected. 


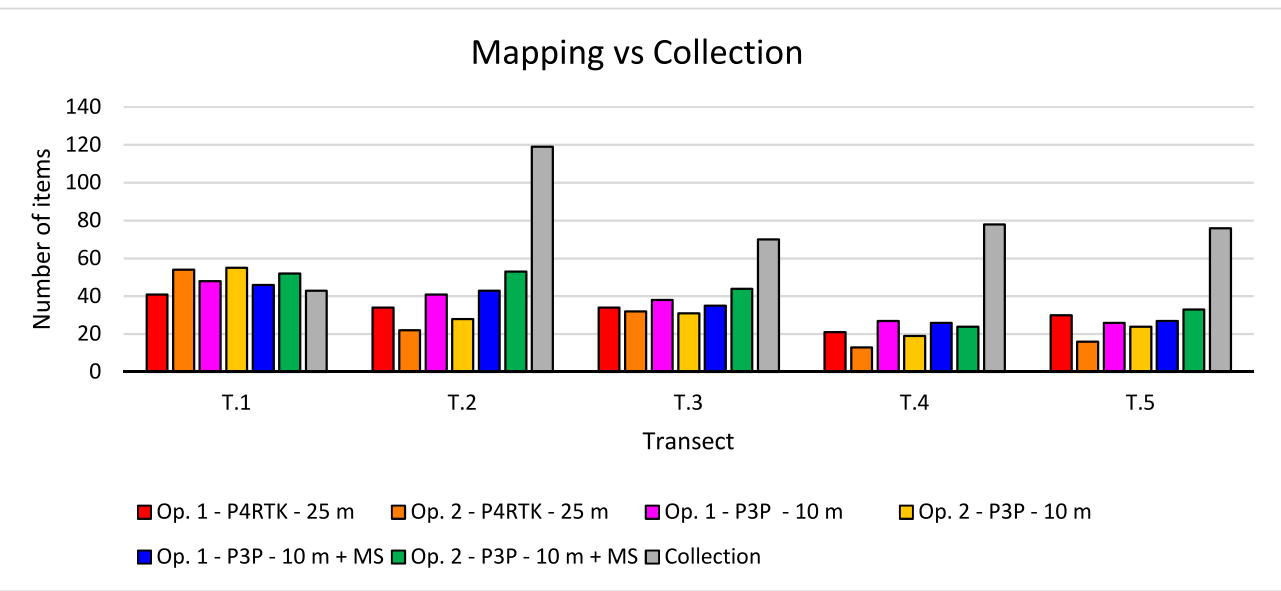

Figure 9. Number of items recognized and collected, per transect (2019).

The amount of AMD, when considering the number of items (i.e., count), is generally underestimated with the sole exception of transect T.1. For transect one, the results of operator 1 and operator 2 are consistent and comparable to the count of collected items.

\subsection{Second Campaign (2020)}

The second beach litter survey results are slightly different from the previous one. Operator 1 assigned a high number of CL 3 (more than $80 \%$ of the total), likely due to the lack of experience in distinguishing natural elements on a beach from potential litter items. Operator 2, still maintaining a considerable percentage of CL 3 items, was able to exploit their experience and knowledge of the beach environment morphology to classify the items with higher confidence. In fact, the percentage of items with CL 3 is lower for operator 2 than operator 1: it decreases from $86 \%$ to $39 \%$ for the dataset acquired with the DJI-P3P at a $10 \mathrm{~m}$ altitude (see Figure 10).
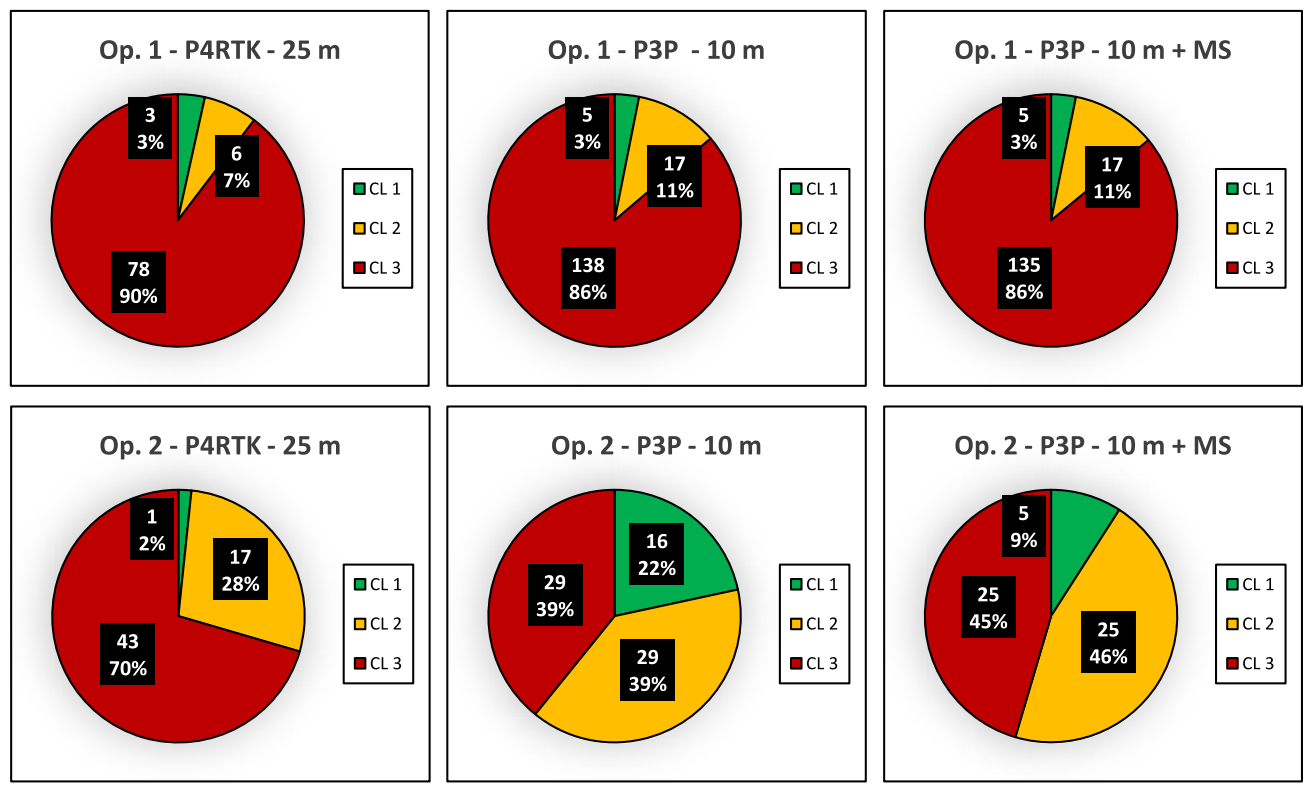

Figure 10. Number of items recognized through manual image mapping by different operators with different image datasets (2020).

Consistently, litter collection provided the actual number of objects that were present in each transect at the time of the survey. Figure 11 shows the total amount of items recognized by the operators. For most transects, operator 2 found a number of items largely different from operator 1 . This is due to the large attribution of CL 3 made by 
operator 1. Even if the total identified object count is better compared to the collected ones than those identified by operator 2, in many cases, the additional items found by operator 1 were not AMD. Giving operator 1 the option of using UAV pictures in addition to the orthomosaic only, in fact, allowed him to exclude about 70 items that were noted using solely the orthomosaic. UAV pictures provided a view of items from different angles, helping the operator in deciding whether the item was in fact litter. However, under these conditions, the mapping task became more time-consuming.

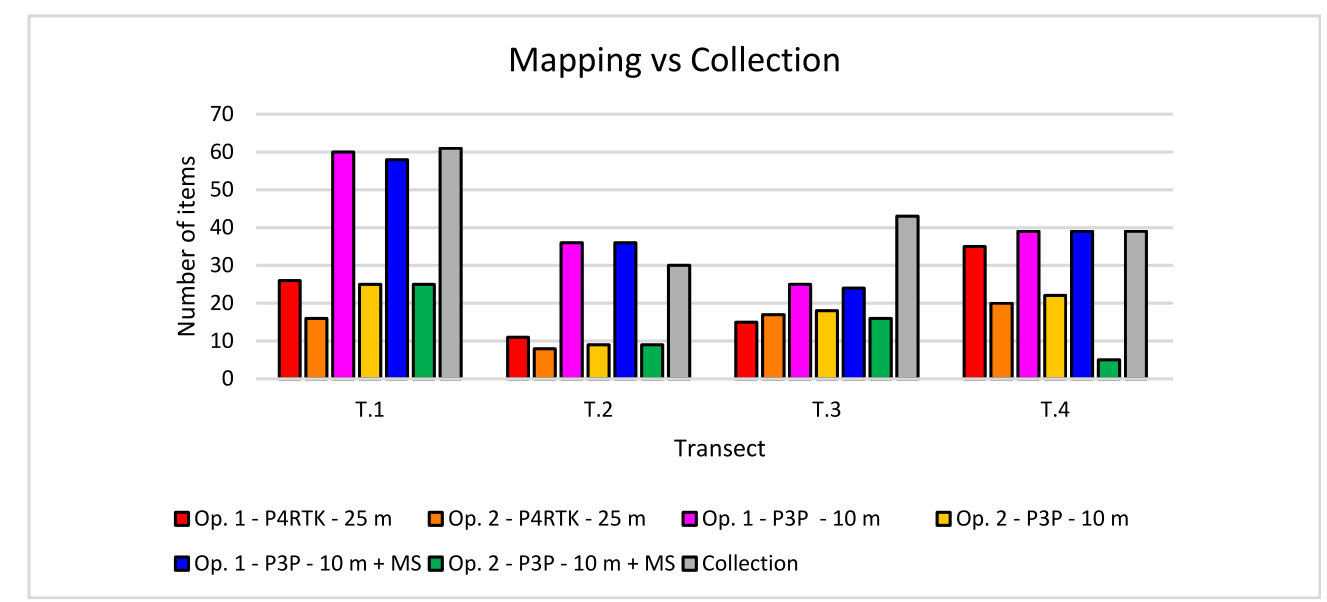

Figure 11. Number of items recognized and collected, per transect (2020).

\subsection{Comparison in Terms of Area}

Focusing on the number of items identified does not take into account the size of each object. Here, we show the litter recognized by the operators with respect to the total collected in terms of area. Moreover, we compare this with the simple count of the same objects (2019 dataset, operator 1 ). Figure 12 shows that accounting for the surface actually covered by each item on the orthomosaics increases the detection of the total AMD up to more than $80 \%$ of the total collected. Larger items, in fact, are easier to identify than very small ones and contribute significantly to the overall litter amount, especially if considering them as a potential source of MP.

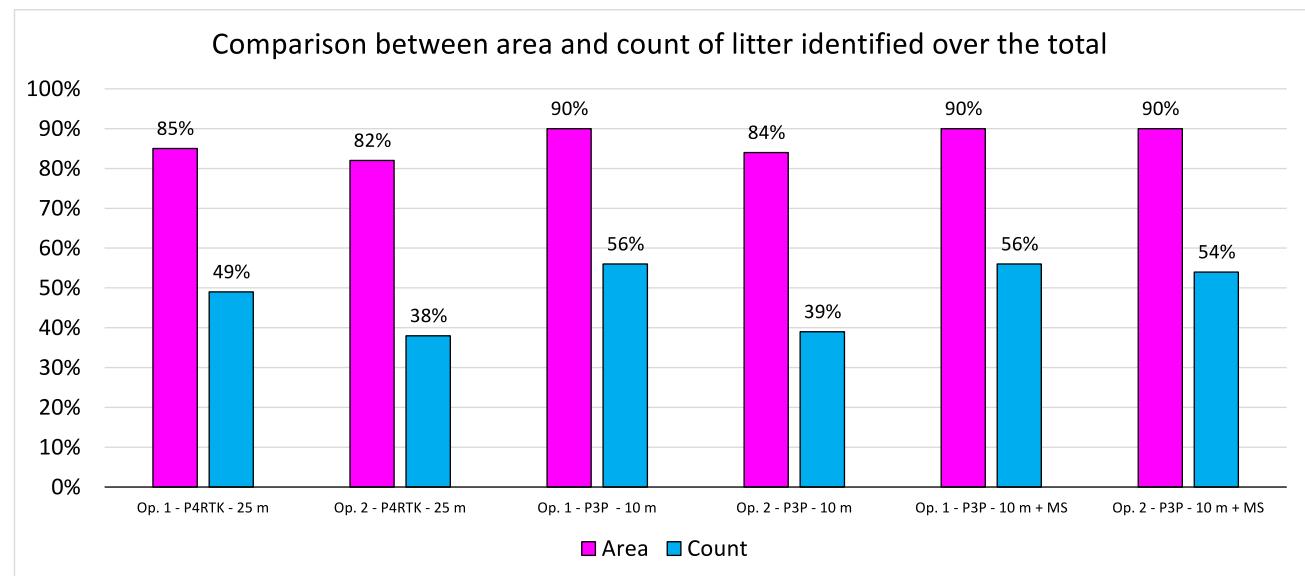

Figure 12. Comparison between area and number of litter items identified through manual mapping over the total of actual litter (2019).

\subsection{Object Identification: Comparisons}

Macroplastic identification and classification provided different accuracy levels in recognizing the objects on the basis of available information. The consequence, as shown above, was to assign a certain CL during the operation of litter description. However, it is particularly interesting to show in which way an item can be recognized or not using the different 
UAV-derived products. Figure 13 shows (i) a picture of detail, (ii) the orthomosaic view, (iii) the DSM, and (iv) the NDVI. Here, we present a brief example of items that can usually be found on beaches, showing how they are recognizable using UAV image-based datasets:

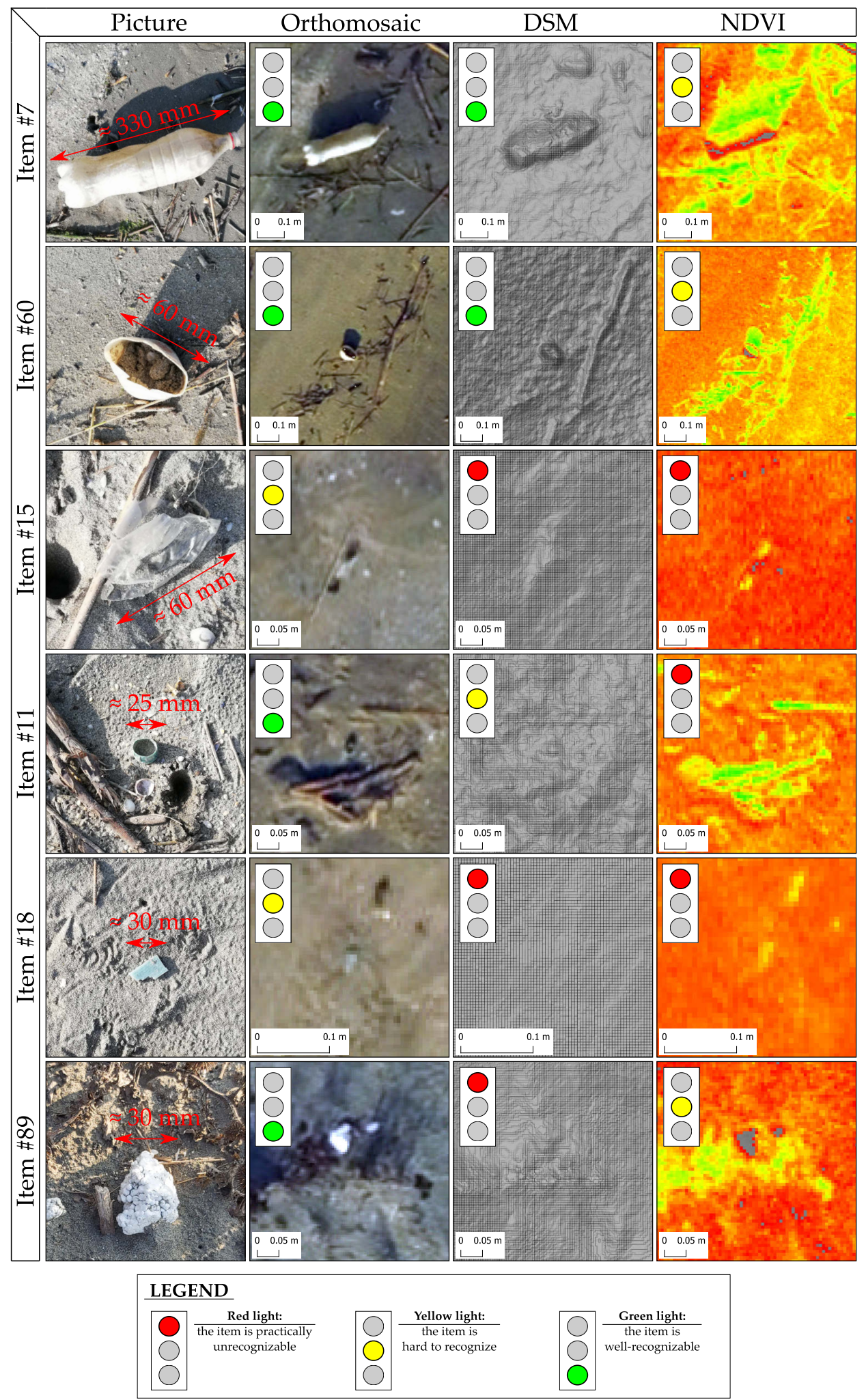

Figure 13. Level of identification of different items of macroplastics (plastic bottles, stoppers, piece of plastic and polystyrene, bags). 
- Item 7-Drink bottle >0.5 L (class G8): the item is recognizable both on the orthomosaic and the DSM and hence easy to identify.

- Item 60-Plastic piece $2.5-50 \mathrm{~cm}$ (class G79): the item is quite easy to identify due to its size, shape, color, and position.

- Item 15-Small plastic bag (class G4): the item is very hard to identify since it is practically indistinguishable from the background.

- Item 11-Plastic cap/lid unidentified (class G23): the item may be recognized using the circular shape. However, the possible presence of sand contained in the object can make detection very hard.

- Item 18-Plastic piece 2.5-50 cm (class G79): the item is close to the lower size of this class and hence very difficult to identify. Color may help.

- Item 89-Polystyrene piece $2.5-50 \mathrm{~cm}$ (class G82): the item is well identifiable on the orthomosaic due to its bright white color. However, the shape does not differ much from the background.

Most of the AMD located on the beach presented situations similar to those depicted in Figure 13.

\section{Discussion}

This article presents an approach based on UAVs for mapping and classifying the plastic AMD along a beach. The survey was repeated after one year, using drone technology to fly over the same transects. AMD over $2.5 \mathrm{~cm}$ was collected every time and further analyzed to create a ground truth dataset. Using UAV images captured at a distance of 10 to $25 \mathrm{~m}$ from the ground surface, we generated orthomosaics, DSMs, and NDVI maps in order to develop a comprehensive AMD map. To better understand the way expertise might influence accuracy with identification, we used operators with varying levels of experience in recognizing AMD. Expertise in marine debris research and identification proved an important difference in determining operator accuracy. operator 1's relative inexpertise was supplemented by UAV-acquired photographs, which improved accuracy.

Assigning a level of confidence to the classification of items proved to be a crucial aspect in monitoring the degree of mapping accuracy. In fact, less confident classifications were often preferred by mapping operators due to the difficulty in distinguishing AMD from the background texture and recognizing it properly. Lo et al. [40] demonstrated that operating conditions also affect the accuracy in litter assessment in a significant way, with an accuracy ranging from $39 \%$ to $75 \%$. The validation of the descriptions of recognized AMD items proved that the operator's attribution of higher CLs was actually matched by a proper identification of AMD. Usually, CL 1 was assigned to items with a well-distinguishable shape. Moreover, the concordance [44] between operators was maximum for CL 1. Larger items such as plastic bottles proved easy to identify on the orthomosaic and the DSM. This is because they cover a large number of pixels, and they also deviate considerably from the terrain topography. White pieces of plastic (e.g., polystyrene) can be distinguished both using the orthomosaic and multispectral information (i.e., NDVI). However, recognizing them on the DSM may be difficult due to their small size and more rounded shape. Stoppers or bottle caps can be distinguished due to their circular shape, but the actual size results in the difference for success in recognizing them. Moreover, the visible side of the stopper is important. In fact, the accumulation of sand accumulated within the stopper can negatively affect the identification process. Flat objects, such as small pieces of plastics, are difficult to distinguish; their color may help in recognizing them on the orthomosaic, though such colors often fade over time and with exposure to the natural elements. Finally, transparent items (e.g., films, bags) are really hard to identify using all of the information acquired. They are often flat, transparent, and can also be partially covered by the sand, all of which make them less distinguishable.

Conversely, recognizing very small items is a very hard task: the spatial resolution on the ground should be increased, but generally this requires flying lower, limiting the extent of any flight mission. While microplastics do not contribute significantly to the 
total amount of AMD in terms of weight, they are an important component of the plastic pollution problem. The value of this approach is based on the mapping and quantification of larger items, representing a solution for a quick mapping of beach AMD.

Multispectral data in the near-infrared wavelengths allowed operators to exclude vegetation-related items such as flowers or stems on the dune but did not increase the amount of AMD recognized in a significant way. On the contrary, looking at the results obtained by the more expert operator 2 in 2020, Figure 10 highlights a decrease of both the total count of AMD in each CL class (CL 3: from 29 to 25; CL 2: from 29 to 25; CL 1: from 16 to 5) and an increase of the uncertainty in classifying the litter (CL 3: from 39\% to $45 \%$; CL 2: from $39 \%$ to $46 \%$; CL 1: from $22 \%$ to $9 \%$ ). The spectral response of litter material has been investigated in controlled laboratory environments [50,51] and leads to the characterization of the plastic [52,53], but the same response in the field [54] can be different due to degradation processes that modify material characteristics. The collection of proximal hyperspectral measurements of in situ plastic debris [55] can represent a way for developing methods to address this issue. Additionally, on the basis of specific wavelengths in which the spectral response is higher than the environmental surroundings, and hence the presence of plastics is characterized by better exploiting this, new spectral indices can be formulated and investigated compared to the simple NDVI. Similarly, the use of DSM in the support of mapping operations did not increase the amount of AMD recognized in a significant way. Although the use of DSMs can allow operators to recognize item shape, even in a semi-automatic way [56], limitations are also represented by natural wood debris, algae agglomeration, and similar items that would result in beach surface anomalies, misleading marine litter detection. Conversely, the use of DSMs allows the quantification of litter volume [57].

The comparison between the mapping performed using DJI-P4RTK and DJI-P3P image datasets showed that, in most cases, using the DJI-P3P, the confidence level assigned to litter items increased. This is quite obviously due to the higher spatial resolution of DJIP3P images at a $10 \mathrm{~m}$ flight altitude (i.e., $G S D_{\text {DJI-P3P }}=4 \mathrm{~mm}<G S D_{\text {DJI-P4RTK }}=7 \mathrm{~mm}$ ). However, the use of an RTK UAV has certainly the notable advantage of speeding up all the aerial survey operations in the field since there is no need to deploy GCPs and collect their coordinates with a GNSS receiver. Current app limitations may be resolved in the future, allowing one to exploit the higher camera resolution of the DJI-P4RTK (i.e., camera resolution $_{\text {DII-P4RTK }}=20 \mathrm{Mpix}>$ camera resolution $_{\text {DJI-P3P }}=12 \mathrm{Mpix}$ ).

The precise positioning of the AMD, on the beach or in wider coastal stretches, also represents important data, especially whenever combined with ground surveys (collected items) because such information is useful to better understand their transport, distribution, and accumulation under coastal processes forcing the overall dynamic system $[38,58,59]$. Moreover, the spatial distribution of AMD mapped using the UAV approach can be further used to calculate beach litter density or CCI to classify beaches on the basis of cleanliness. The UAV-based AMD mapping can help in cataloging and better understanding debris that might exist in hard to access places. Finally, we believe that a UAV-designed list of litter items, as the one proposed by Andriolo et al. [44], should be refined and assumed as a standard for UAV-based mapping and monitoring of AMD in the future, both to help users with poor experience in litter monitoring (as in this work) and to make UAV survey output uniform.

\section{Conclusions}

The mapping of AMD from UAVs is strongly influenced by the relationship between the ground sample distance and the size of litter. In this work, we found that a resolution of about $200 \mathrm{pix} / \mathrm{m}$ is a good solution to map plastic debris. That said, the characteristics and the position of items on the ground affect the detection of even large and theoretically easy-to-identify objects. Moreover, the level of experience of the mapping operator is a further variable that can impact the results of litter identification. The use of multispectral information can help to distinguish vegetation from AMD but was found to be substantially 
unhelpful in distinguishing AMD from the sandy background. There are inherent tradeoffs in the choices made using this methodology. Focusing on large items can yield accurate results while flying over wide areas. Focusing on smaller areas at closer range can allow better quantifying debris of various sizes. Due to the operator's uncertainty in recognizing the AMD properly on the orthomosaics, operator training should be required in order to improve their confidence with UAV-based AMD mapping.

Based on this analysis, we recommend (i) to use RGB cameras with the highest geometric resolution as possible in order to have smaller ground sample distances, (ii) to use RTK drones if a centimeter-level accuracy of debris position has to be achieved, and (iii) not to use operators with no experience in matters of beach litter mapping when using drone technology to identify anthropogenic marine debris.

Future research should explore the use of hyperspectral sensors $[60,61]$ instead of multispectral ones in order to exploit ways that some plastics respond to specific wavelengths as well as the use of algorithms of object detection, machine learning [11,62-67], or a deep-feature-based approach [68] coupled with this type of imaging. However, these tasks can be complicated by the degradation processes which modify the characteristics of materials, plastics included. The spectral response in situ can be different from what is obtained in the laboratory.

Author Contributions: Conceptualization, Y.T., C.C. and A.P.; data curation, Y.T., C.C., J.B. and A.P.; formal analysis, Y.T., C.C. and A.P.; funding acquisition, C.C., U.S. and A.P.; investigation, Y.T., C.C., J.B. and A.P.; methodology, Y.T., C.C. and A.P.; project administration, C.C., U.S. and A.P.; resources, Y.T., C.C., U.S. and A.P.; software, Y.T. and A.P.; supervision, Y.T., C.C., U.S. and A.P.; validation, Y.T., C.C. and A.P.; visualization, Y.T.; writing—original draft preparation, Y.T.; writing-review and editing, Y.T., C.C. and A.P.; All authors have read and agreed to the published version of the manuscript.

Funding: This study was supported by the NET4mPLASTIC project, co-financed by the European Regional Development Fund within the framework of European cross-border territorial cooperation Interreg. IT-HR. CUP: F76C19000000007.

Institutional Review Board Statement: Not applicable.

Informed Consent Statement: Not applicable.

Data Availability Statement: Not applicable.

Acknowledgments: The authors would like to thank students and technical staff involved in support of operations in the field.

Conflicts of Interest: The authors declare no conflict of interest. The funders had no role in the design of the study; in the collection, analyses, or interpretation of data; in the writing of the manuscript; or in the decision to publish the results.

\begin{tabular}{|c|c|}
\hline \multicolumn{2}{|c|}{ Abbreviations } \\
\hline The follov & abbreviations are used in this mar \\
\hline AMD & Anthropogenic Marine Debris \\
\hline CCI & Clean-Coast Index \\
\hline CL & Confidence Level \\
\hline DJI-P3P & DJI Phantom 3 Professional \\
\hline DJI-P4RTK & DJI Phantom 4 RTK \\
\hline DSM & Digital Surface Model \\
\hline ETRF & European Terrestrial Reference Frame \\
\hline ETRS & European Terrestrial Reference System \\
\hline GCP & Ground Control Point \\
\hline GIS & Geographic Information System \\
\hline GNSS & Global Navigation Satellite System \\
\hline GSD & Ground Sample Distance \\
\hline $\mathrm{MP}(\mathrm{s})$ & Microplastic(s) \\
\hline MS & Multispectral \\
\hline
\end{tabular}




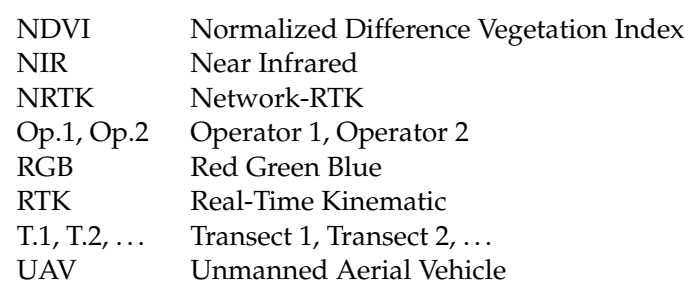

\section{References}

1. Rangel-Buitrago, N.; Arroyo-Olarte, H.; Trilleras, J.; Arana, V.A.; Mantilla-Barbosa, E.; Gracia, C.A.; Mendoza, A.V.; Neal, W.J.; Williams, A.T.; Micallef, A. Microplastics pollution on Colombian Central Caribbean beaches. Mar. Pollut. Bull. 2021, 170, 112685, [CrossRef] [PubMed]

2. Rangel-Buitrago, N.; Gracia C.A.; Vélez-Mendoza, A.; Mantilla-Barbosa, E.; Arana, V.A.; Trilleras, J.; Arroyo-Olarte, H. Abundance and distribution of beach litter along the Atlantico Department, Caribbean coast of Colombia. Mar. Pollut. Bull. 2018, 136, 435-447. [CrossRef] [PubMed]

3. Roman, L.; Warmbrunn, A.; Lawson, T.; Willis, K.; Wilcox, C.; Hardesty, B.D. Comparing marine anthropogenic debris on inhabited mainland beaches, coastal islands, and uninhabited offshore islands: A case study from Queensland and the Coral Sea, Australia. Mar. Pollut. Bull. 2021, 172, 112919, [CrossRef] [PubMed]

4. Barnardo, T.; van Niekerk, T.M.; Pichegru, L.; Marlin, D. The first baseline estimation of marine litter in Port Elizabeth, South Africa. Mar. Pollut. Bull. 2021, 172, 112903, [CrossRef] [PubMed]

5. Finger, J.V.G.; Corá, D.H.; Convey, P.; Cruz, F.S.; Petry, M.V.; Krüger, L. Anthropogenic debris in an Antarctic Specially Protected Area in the maritime Antarctic. Mar. Pollut. Bull. 2021, 172, 112921, [CrossRef]

6. Bissen, R.; Chawchai, S. Microplastics on beaches along the eastern Gulf of Thailand-A preliminary study. Mar. Pollut. Bull. 2020, 157, 111345. [CrossRef]

7. Mallory, M.L.; Baak, J.; Gjerdrum, C.; Mallory, O.E.; Manley, B.; Swan, C.; Provencher, J.F. Anthropogenic litter in marine waters and coastlines of Arctic Canada and West Greenland. Sci. Total Environ. 2021, 783, 146971. [CrossRef] [PubMed]

8. Hernández-Sánchez, C.; González-Sálamo, J.; Díaz-Peña, F.J.; Fraile-Nuez, E.; Hernández-Borges, J. Arenas Blancas (El Hierro island), a new hotspot of plastic debris in the Canary Islands (Spain). Mar. Pollut. Bull. 2021, 169, 112548. [CrossRef]

9. Gall, S.; Thompson, R. The impact of debris on marine life. Mar. Pollut. Bull. 2015, 92, 170-179. [CrossRef]

10. Salgado-Hernanz, P.M.; Bauzà, J.; Alomar, C.; Compa, M.; Romero, L.; Deudero, S. Assessment of marine litter through remote sensing: Recent approaches and future goals. Mar. Pollut. Bull. 2021, 168, 112347. [CrossRef]

11. Fallati, L.; Polidori, A.; Salvatore, C.; Saponari, L.; Savini, A.; Galli, P. Anthropogenic Marine Debris assessment with Unmanned Aerial Vehicle imagery and deep learning: A case study along the beaches of the Republic of Maldives. Sci. Total Environ. 2019, 693, 133581. [CrossRef]

12. Penca, J. European Plastics Strategy: What promise for global marine litter? Mar. Policy 2018, 97, 197-201. [CrossRef]

13. Li, C.; Zhu, L.; Wang, X.; Liu, K.; Li, D. Cross-oceanic distribution and origin of microplastics in the subsurface water of the South China Sea and Eastern Indian Ocean. Sci. Total Environ. 2022, 805, 150243. [CrossRef] [PubMed]

14. Saladié, S.; Bustamante, E. Abundance and Composition of Marine Litter on the Seafloor of the Gulf of Sant Jordi (Western Mediterranean Sea). Environments 2021, 8, 106. [CrossRef]

15. Asensio-Montesinos, F.; Anfuso, G.; Aguilar-Torrelo, M.T.; Oliva Ramírez, M. Abundance and Temporal Distribution of Beach Litter on the Coast of Ceuta (North Africa, Gibraltar Strait). Water 2021, 13, 2739. [CrossRef]

16. Expósito, N.; Rovira, J.; Sierra, J.; Folch, J.; Schuhmacher, M. Microplastics levels, size, morphology and composition in marine water, sediments and sand beaches. Case study of Tarragona coast (western Mediterranean). Sci. Total Environ. 2021, 786, 147453. [CrossRef]

17. Ryan, P.; Moore, C.; Van Franeker, J.; Moloney, C. Monitoring the abundance of plastic debris in the marine environment. Philos. Trans. R. Soc. Biol. Sci. 2009, 364, 1999-2012. [CrossRef]

18. Suaria, G.; Aliani, S. Floating debris in the Mediterranean Sea. Mar. Pollut. Bull. 2014, 86, 494-504. [CrossRef]

19. Ramirez-Llodra, E.; De Mol, B.; Company, J.B.; Coll, M.; Sardà, F. Effects of natural and anthropogenic processes in the distribution of marine litter in the deep Mediterranean Sea. Prog. Oceanogr. 2013, 118, 273-287. [CrossRef]

20. Ma, X.; Zhou, Y.; Yang, L.; Tong, J. A Survey of Marine Coastal Litters around Zhoushan Island, China and Their Impacts. J. Mar. Sci. Eng. 2021, 9, 183. [CrossRef]

21. Abude, R.R.; Augusto, M.; Cardoso, R.S.; Cabrini, T.M. Spatiotemporal variability of solid waste on sandy beaches with different access restrictions. Mar. Pollut. Bull. 2021, 171, 112743. [CrossRef] [PubMed]

22. Hengstmann, E.; Gräwe, D.; Tamminga, M.; Fischer, E.K. Marine litter abundance and distribution on beaches on the Isle of Rügen considering the influence of exposition, morphology and recreational activities. Mar. Pollut. Bull. 2017, 115, 297-306. [CrossRef]

23. Williams, A.T.; Randerson, P.; Di Giacomo, C.; Anfuso, G.; Macias, A.; Perales, J.A. Distribution of beach litter along the coastline of Cádiz, Spain. Mar. Pollut. Bull. 2016, 107, 77-87. [CrossRef] [PubMed] 
24. Simeonova, A.; Chuturkova, R.; Yaneva, V. Seasonal dynamics of marine litter along the Bulgarian Black Sea coast. Mar. Pollut. Bull. 2017, 119, 110-118. [CrossRef]

25. Poeta, G.; Battisti, C.; Acosta, A.T. Marine litter in Mediterranean sandy littorals: Spatial distribution patterns along central Italy coastal dunes. Mar. Pollut. Bull. 2014, 89, 168-173. [CrossRef]

26. Rosas, E.; Martins, F.; Janeiro, J. Marine Litter on the Coast of the Algarve: Main Sources and Distribution Using a Modeling Approach. J. Mar. Sci. Eng. 2021, 9, 412. [CrossRef]

27. Fetisov, S.; Chubarenko, I. Marine Litter Stormy Wash-Outs: Developing the Neural Network to Predict Them. Pollutants 2021, 1, 13, [CrossRef]

28. Hartmann, N.B.; Hüffer, T.; Thompson, R.C.; Hassellöv, M.; Verschoor, A.; Daugaard, A.E.; Rist, S.; Karlsson, T.; Brennholt, N.; Cole, M.; et al. Are We Speaking the Same Language? Recommendations for a Definition and Categorization Framework for Plastic Debris. Environ. Sci. Technol. 2019, 53, 1039-1047. [CrossRef]

29. Hanke, G.; Galgani, F.; Werner, S.; Oosterbaan, L.; Nilsson, P.; Fleet, D.; Kinsey, S.; Thompson, R.; Palatinus, A.; Van Franeker, J.; et al. Guidance on Monitoring of Marine Litter in European Seas; EUR 26113; Publications Office of the European Union: Luxembourg, 2013.

30. Vázquez-Rowe, I.; Ita-Nagy, D.; Kahhat, R. Microplastics in fisheries and aquaculture: Implications to food sustainability and safety. Curr. Opin. Green Sustain. Chem. 2021, 29, 100464. [CrossRef]

31. Andrady, A.L. Microplastics in the marine environment. Mar. Pollut. Bull. 2011, 62, 1596-1605. [CrossRef]

32. Nurhasanah; Cordova, M.R.; Riani, E. Micro- and mesoplastics release from the Indonesian municipal solid waste landfill leachate to the aquatic environment: Case study in Galuga Landfill Area, Indonesia. Mar. Pollut. Bull. 2021, 163, 111986. [CrossRef]

33. Guerranti, C.; Perra, G.; Martellini, T.; Giari, L.; Cincinelli, A. Knowledge about Microplastic in Mediterranean Tributary River Ecosystems: Lack of Data and Research Needs on Such a Crucial Marine Pollution Source. J. Mar. Sci. Eng. 2020, 8, 216 [CrossRef]

34. Fondazione Centro Euro-Mediterraneo sui Cambiamenti Climatici (CMCC). DeFishGear-Derelict Fishing Gear Management System in the Adriatic Region. Available online: https:/ / www.cmcc.it/it/projects/defishgear-derelict-fishing-gear-managementsystem-in-the-adriatic-region (accessed on 1 June 2021).

35. Vlachogianni, T.; Anastasopoulou, A.; Fortibuoni, T.; Ronchi, F.; Zeri, C. Marine Litter Assessment in the Adriatic and Ionian Seas; IPA-Adriatic DeFishGear Project, MIO-ECSDE, HCMR and ISPRA; 2017; pp. 1-168; ISBN 978-960-6793-25-7.

36. Alkalay, R.; Pasternak, G.; Zask, A. Clean-coast index-A new approach for beach cleanliness assessment. Ocean. Coast. Manag. 2007, 50, 352-362. [CrossRef]

37. Hidalgo-Ruz, V.; Gutow, L.; Thompson, R.C.; Thiel, M. Microplastics in the Marine Environment: A Review of the Methods Used for Identification and Quantification. Environ. Sci. Technol. 2012, 46, 3060-3075. [CrossRef] [PubMed]

38. Andriolo, U.; Gonçalves, G.; Sobral, P.; Fontán-Bouzas, A.; Bessa, F. Beach-dune morphodynamics and marine macro-litter abundance: An integrated approach with Unmanned Aerial System. Sci. Total Environ. 2020, 749, 141474. [CrossRef] [PubMed]

39. Martin, C.; Parkes, S.; Zhang, Q.; Zhang, X.; McCabe, M.F.; Duarte, C.M. Use of unmanned aerial vehicles for efficient beach litter monitoring. Mar. Pollut. Bull. 2018, 131, 662-673. [CrossRef]

40. Lo, H.S.; Wong, L.C.; Kwok, S.H.; Lee, Y.K.; Po, B.H.K.; Wong, C.Y.; Tam, N.F.Y.; Cheung, S.G. Field test of beach litter assessment by commercial aerial drone. Mar. Pollut. Bull. 2020, 151, 110823. [CrossRef] [PubMed]

41. Fairley, I.; Horrillo-Caraballo, J.; Masters, I.; Karunarathna, H.; Reeve, D.E. Spatial Variation in Coastal Dune Evolution in a High Tidal Range Environment. Remote Sens. 2020, 12, 3689. [CrossRef]

42. Taddia, Y.; Corbau, C.; Zambello, E.; Russo, V.; Simeoni, U.; Russo, P.; Pellegrinelli, A. UAVs to Assess the Evolution of Embryo Dunes. Int. Arch. Photogramm. Remote Sens. Spat. Inf. Sci. 2017, XLII-2/W6, 363-369. [CrossRef]

43. Taddia, Y.; Pellegrinelli, A.; Corbau, C.; Franchi, G.; Staver, L.W.; Stevenson, J.C.; Nardin, W. High-Resolution Monitoring of Tidal Systems Using UAV: A Case Study on Poplar Island, MD (USA). Remote Sens. 2021, 13, 1364. [CrossRef]

44. Andriolo, U.; Gonçalves, G.; Rangel-Buitrago, N.; Paterni, M.; Bessa, F.; Gonçalves, L.M.; Sobral, P.; Bini, M.; Duarte, D.; FontánBouzas, A.; et al. Drones for litter mapping: An inter-operator concordance test in marking beached items on aerial images. Mar. Pollut. Bull. 2021, 169, 112542. [CrossRef]

45. Escobar-Sánchez, G.; Haseler, M.; Oppelt, N.; Schernewski, G. Efficiency of Aerial Drones for Macrolitter Monitoring on Baltic Sea Beaches. Front. Environ. Sci. 2021, 8, 283. [CrossRef]

46. Merlino, S.; Paterni, M.; Berton, A.; Massetti, L. Unmanned Aerial Vehicles for Debris Survey in Coastal Areas: Long-Term Monitoring Programme to Study Spatial and Temporal Accumulation of the Dynamics of Beached Marine Litter. Remote Sens. 2020, 12, 1260. [CrossRef]

47. Taddia, Y.; Stecchi, F.; Pellegrinelli, A. Coastal Mapping Using DJI Phantom 4 RTK in Post-Processing Kinematic Mode. Drones 2020, 4, 9. [CrossRef]

48. Taddia, Y.; González-García, L.; Zambello, E.; Pellegrinelli, A. Quality Assessment of Photogrammetric Models for Façade and Building Reconstruction Using DJI Phantom 4 RTK. Remote Sens. 2020, 12, 3144. [CrossRef]

49. Forlani, G.; Dall'Asta, E.; Diotri, F.; Cella, U.M.D.; Roncella, R.; Santise, M. Quality Assessment of DSMs Produced from UAV Flights Georeferenced with On-Board RTK Positioning. Remote Sens. 2018, 10, 311. [CrossRef]

50. Moshtaghi, M.; Knaeps, E.; Sterckx, S.; Garaba, S.; Meire, D. Spectral reflectance of marine macroplastics in the VNIR and SWIR measured in a controlled environment. Sci. Rep. 2021, 11, 5436. [CrossRef] 
51. Corbari, L.; Maltese, A.; Capodici, F.; Mangano, M.; Sarà, G.; Ciraolo, G. Indoor spectroradiometric characterization of plastic litters commonly polluting the Mediterranean Sea: Toward the application of multispectral imagery. Sci. Rep. 2020, 10. [CrossRef]

52. Balsi, M.; Esposito, S.; Moroni, M. Hyperspectral characterization of marine plastic litters. In Proceedings of the 2018 IEEE International Workshop on Metrology for the Sea; Learning to Measure Sea Health Parameters (MetroSea), Bari, Italy, 8-10 October 2018; pp. 28-32. [CrossRef]

53. Serranti, S.; Palmieri, R.; Bonifazi, G.; Cózar, A. Characterization of microplastic litter from oceans by an innovative approach based on hyperspectral imaging. Waste Manag. 2018, 76, 117-125. [CrossRef]

54. Faizal, A.; Samad, W.; Werorilangi, S. Visible reflectance characteristics of marine debris in the sandy beach. J. Phys. Conf. Ser. 2019, 1341, 022011. [CrossRef]

55. Guffogg, J.A.; Soto-Berelov, M.; Jones, S.D.; Bellman, C.J.; Lavers, J.L.; Skidmore, A.K. Towards the Spectral Mapping of Plastic Debris on Beaches. Remote Sens. 2021, 13. [CrossRef]

56. Ge, Z.; Shi, H.; Mei, X.; Dai, Z.; Li, D. Semi-automatic recognition of marine debris on beaches. Sci. Rep. 2016, 6. [CrossRef] [PubMed]

57. Kako, S.; Morita, S.; Taneda, T. Estimation of plastic marine debris volumes on beaches using unmanned aerial vehicles and image processing based on deep learning. Mar. Pollut. Bull. 2020, 155, 111127. [CrossRef] [PubMed]

58. Andriolo, U.; Gonçalves, G.; Sobral, P.; Bessa, F. Spatial and size distribution of macro-litter on coastal dunes from drone images: A case study on the Atlantic coast. Mar. Pollut. Bull. 2021, 169, 112490. [CrossRef] [PubMed]

59. Martin, C.; Zhang, Q.; Zhai, D.; Zhang, X.; Duarte, C.M. Enabling a large-scale assessment of litter along Saudi Arabian red sea shores by combining drones and machine learning. Environ. Pollut. 2021, 277, 116730. [CrossRef]

60. Freitas, S.; Silva, H.; Silva, E. Remote Hyperspectral Imaging Acquisition and Characterization for Marine Litter Detection. Remote Sens. 2021, 13, 2536. [CrossRef]

61. Balsi, M.; Moroni, M.; Chiarabini, V.; Tanda, G. High-Resolution Aerial Detection of Marine Plastic Litter by Hyperspectral Sensing. Remote Sens. 2021, 13, 1557. [CrossRef]

62. Gonçalves, G.; Andriolo, U.; Pinto, L.; Duarte, D. Mapping marine litter with Unmanned Aerial Systems: A showcase comparison among manual image screening and machine learning techniques. Mar. Pollut. Bull. 2020, 155, 111158. [CrossRef]

63. Gonçalves, G.; Andriolo, U.; Pinto, L.; Bessa, F. Mapping marine litter using UAS on a beach-dune system: A multidisciplinary approach. Sci. Total Environ. 2020, 706, 135742. [CrossRef]

64. Jakovljevic, G.; Govedarica, M.; Alvarez-Taboada, F. A Deep Learning Model for Automatic Plastic Mapping Using Unmanned Aerial Vehicle (UAV) Data. Remote Sens. 2020, 12, 1515. [CrossRef]

65. Garcia-Garin, O.; Monleón-Getino, T.; López-Brosa, P.; Borrell, A.; Aguilar, A.; Borja-Robalino, R.; Cardona, L.; Vighi, M. Automatic detection and quantification of floating marine macro-litter in aerial images: Introducing a novel deep learning approach connected to a web application in R. Environ. Pollut. 2021, 273, 116490. [CrossRef] [PubMed]

66. Wolf, M.; van den Berg, K.; Garaba, S.P.; Gnann, N.; Sattler, K.; Stahl, F.; Zielinski, O. Machine learning for aquatic plastic litter detection, classification and quantification (APLASTIC-Q). Environ. Res. Lett. 2020, 15, 114042. [CrossRef]

67. Pinto, L.; Andriolo, U.; Gonçalves, G. Detecting stranded macro-litter categories on drone orthophoto by a multi-class Neural Network. Mar. Pollut. Bull. 2021, 169, 112594. [CrossRef] [PubMed]

68. Marin, I.; Mladenović, S.; Gotovac, S.; Zaharija, G. Deep-Feature-Based Approach to Marine Debris Classification. Appl. Sci. 2021, 11, 5644. [CrossRef] 